\title{
Analisis Kualitas Distribusi Air Menggunakan Metode Six Sigma DMAIC pada PDAM Surya Sembada Kota Surabaya
}

\author{
Evi Maria Ulfah \\ Universitas Airlangga \\ Tuwanku Aria Auliandri \\ Universitas Airlangga \\ aria@feb.unair.ac.id
}

\begin{abstract}
Abstrak
PDAM Surya Sembada Surabaya is a water supply company. This company distributes and supplies hygienic water to all residents in Surabaya. PDAM Surya Sembada Surabaya always tries to make customers satisfied with the provided services. Moreover, the company also tries to continue the improvements based on the management quality of ISO 9001: 2008. However, in the process of water distribution, some customers are still complaining due to the PDAM's service, which indicates that not all the customers are satisfied. It is the duty of PDAM Surabaya to improve the quality services. This study focuses on providing the causes defects analysis of PDAM Surabaya Surya Sembada water distribution using the Six Sigma DMAIC. This study used descriptive qualitative approach with an emphasis on the question of how. The results of the research proved that there are two defects in the water distribution change into CTQ; defect TDA (No Water) and IMR (stench muddy water). In 2015, performance of Surabaya PDAM Surya Sembada showed the DPMO value as 844 and the value of capability sigma as 4.64. Based on Pareto diagram, this study stated that the dominant defect is TDA. This study applied the basic cause effect diagram to show the defect cause problem and used FMEA as a recommendation for continuous improvement that is expected to achieve zero defects.
\end{abstract}

Keywords: Six Sigma, defect, DMAIC, DPMO, value of capability sigma, CTQ, Pareto charts, cause and effect diagram, FMEA.

\section{Pendahuluan}

\section{Latar Belakang}

Perusahaan Daerah Air Minum (PDAM) adalah salah satu bentuk badan usaha milik daerah (BUMD) yang bergerak pada bidang pelayanan pemanfaatan umum di bidang penyediaan dan distribusi air bersih. Sebagai penyedia layanan PDAM harus dapat memahami dan memberikan apa yang diinginkan oleh pelanggan agar Pelanggan merasa puas dengan penyedia layanan. Mengendalikan kualitas adalah cara untuk dapat memuaskan pelanggan. Kualitas yang baik akan membuat pelanggan menjadi puas sehingga membuat pelanggan menjadi loyal dan selanjutnya membawa keuntungan sendiri untuk penyedia layanan.

Kualitas menurut American society for quality control's (dalam Kotler, 2009.) adalah keseluruhan fitur dan karakteristik produk atau jasa,yang mampu memuaskan atau memenuhi kebutuhan-kebutuhan yang telah ditetapkan.

Six Sigma adalah metodologi formal dan ketat yang bertujuan mengurangi variasi proses untuk memastikan kepuasan pelanggan, pengurangan biaya dan profitabilitas organisasi. Filosofi Six Sigma adalah untuk memantau proses terus menerus dan bertujuan menghilangkan dan mengurangi defect (cacat) atau kegagalan dari proses manufaktur. Defect didefenisikan sebagai penyimpangan dalam kinerja Critical to quality (CTQ). Six Sigma 
menganalisis variasi di tahap pengolahan untuk mengurangi cacat kurang dari 3,4 cacat per juta kesempatan (DPMO). (Srinavasan et al., 2014).

Salah satu metode pendekatan untuk penerapan six sigma adalah metode DMAIC. Metode Six Sigma DMAIC, digunakan untuk memperbaiki proses yang ada telah terbukti berhasil dalam mengurangi biaya, menghilangkan cacat, meningkatkan kepuasan pelanggan dan secara signifikan meningkatkan profitabilitas di setiap industri dan banyak organisasi di seluruh dunia (Tong et al., 2004 dalam Prashar 2014).

PDAM Surya Sembada Kota Surabaya berlokasi di Jalan Mayjend Prof. Dr.

Moestopo No. 2. PDAM Surya Sembada Kota Surabaya bertugas memproduksi dan mendistribusi air bersih untuk kebutuahan warga Kota Surabaya. Sumber Utama air PDAM Surya Sembada Kota Surabaya untuk mengairi wilayah Surabaya berasal dari Kali Surabaya. Di daerah Surabaya wilayah pelayanan terbagi menjadi zona 1 sampai 5 zona pelayanan, dan 148 subzona (Company Profile PDAM).

Pada proses pelayanan di PDAM Surya Sembada Kota Surabaya masih terdapat beberapa keluhan-keluhan khususnya pada kualitas air yang dihasilkan, seperti AKB (air keruh dan bau) dan TDA (Tidak Dapat Air). Hal ini menjadi tugas bagi PDAM Surya Sembada Kota Surabaya untuk melakukan perbaikan kualitas pada produk air (Data PDAM Surya Sembada Kota Surabaya, 2015).

Berdasarkan uraian diatas maka penulis menganggap penelitian tentang analisis kualitas pada distribusi air dengan metode six sigma DMAIC perlu dilakukan untuk menigkatkan kualitas dan mengurangi tingkat defect yang terjadi. Penelitian ini bertujuan untuk melakukan perbaikan kualitas dan pengurangan tingkat defect dalam hal distribusi air di PDAM Surya Sembada Kota Surabaya.

\section{Rumusan Masalah}

Berdasarkan dari latar belakang yang diuraikan, maka dirumuskan permasalahan sebagai berikut: "Bagaimana analisis kualitas proses distribusi air PDAM Surya Sembada Kota Surabaya mengunakan metode six sigma DMAIC" ?

\section{Tujuan Penelitian}

Tujuan yang ingin dicapai dalam penelitian ini adalah:

1. Mengetahui faktor penyebab defect yang terjadi pada produk air di PDAM Surya Sembada Kota Surabaya.

2. Mengetahui peran six sigma DMAIC dalam proses perbaikan produk air.

3. Mengetahui solusi dan usulan perbaikan untuk menangani masalah defect yang terjadi pada distribusi air PDAM Surya Sembada Kota Surabaya.

\section{Tinjauan Pustaka \\ Kualitas \\ Definisi Kualitas}

Feigenbaum (dalam Nasution,2005:3) menyatakan, bahwa kualitas adalah kepuasan pelanggan sepenuhnya (full customer satisfaction). Suatu produk berkualitas apabila dapat memberi kepuasan sepenuhnya pada konsumen, yaitu sesuai dengan apa yang diharapkan konsumen atas suatu produk.

\section{Persepsi Terhadap Kualitas}

David Garvin (dalam Hakserver 2013) mengidentifikasikan adanya lima alternatif perspektif kualitas yang biasa digunakan, yaitu: Transcendent, Produced Based, User-based. Manufacturing-based, dan Value-based. 


\section{Kualitas Produk}

Menurut David Garvin (1987), dalam (Sebastianelli \& Timmi, 2002) ada delapan dimensi agar sebuah perusahaan dapat membuat produk yang"berkualitas". yaitu: Performance,Features, Serviceabilit, Aesthetics,Perceived Quality, Conformance, Reliability dan Durability.

\section{Perbaikan Kualitas}

Menurut Besterfield (2003) terdapat berbagai jenis perbaikan yaitu: Mendapatkan nilai tambah dari penguna layanan melalui produk atau jasa yang baru maupun yang sudah ada, Mengurangi kesalahan, cacat, dan eliminasi, Memperbaiki kinerja, Memperbaiki produktivitas dan efektifitas dalam penggunaan sumber daya, Memperbaiki kepemimpinan dalam memenuhi tanggung jawab publik.

\section{Manfaat Perbaikan Kualitas}

Manfaat kualitas bagi organisasi menurut Hakserver (2013) yaitu: Tingginya konsumen yang loyal, Tingginya pangsa pasar, Tingginya pengembalian investor, loyalitas pekerja, Biaya yang rendah, dan Kerentanan terhadap persaingan harga.

\section{Defect}

Defect (kecacatan/rusak) menurut Pande (2000) defect adalah semua contoh atau kejadian produk atau jasa gagal memenuhi persyaratan pelanggan.

\section{DPO (Defect per oppurtunity)}

DPO (Defect per oppurtunity) adalah ukuran kegagalan yang menunjukkan banyaknya cacat atau kegagalan per satu kesempatan. DPO dihitung dengan menggunakan rumus.

$$
\mathrm{DPO}=\frac{\text { Banyaknya kegagalan }}{\text { CTQX Banyaknya unit yang diperiksa }}
$$

Ket:CTQ (Critical-to-quality)=Unit yang diperiksa

\section{DPMO (Defect per Million Opportunity)}

Defect per Million Opportunity (DPMO) merupakan ukuran kegagalan yang menunjukkan kegagalan per satu juta kesempatan.

$$
\mathrm{DPMO}=\quad \frac{\text { Banyaknya kegagalan }}{\text { CTQ } X \text { Banyaknya unit yang diperiksa }} \times 1000.000
$$

\section{Six Sigma \\ Definisi Six Sigma}

Six sigma adalah sebuah sistem yang komprehensif dan fleksibel untuk mencapai, mempertahankan dan memaksimalkan kesuksesan bisnis. Six sigma secara unik dikendalikan oleh pemahamn yang kuat terhadap kebutuhan pelanggan. Pemakaian yang disiplin terhadap fakta dan analisis statistik, dan perhatian yang cermat untuk mengelola menanamkan kembali proses bisnis (Pande et al., 2000).

\section{DMAIC Six sigma}

Define. Tahap ini dalam proses DMAIC melibatkan mendefinisikan peran tim,lingkup proyek dan batasanya,kebutuhan pelanggan dan harapan,tujuan dari proyek yang dipilih (Gijo et al., 2011 dalam Jirasukprasert et al., 2014). 
Measure. Tahap ini meliputi memilih faktor pengukuran ditingkatkan (Omachonu dan Ross, 2004) dan menyediakan struktur untuk mengevaluasi arus kinerja serta menilai membandingkan dan pemantauan selanjutnya perbaikan dan kemampuan mereka (Stamatis, 2004 dalam Jirasukprasert et al., 2014).

Analyse. Tahap ini pusat dalam menentukan akar penyebab masalah (cacat)(Omachonu dan Ross, 2004), memahami mengapa cacat terjadi serta memprioritaskan masalah yang akn dipecahkan (Adamsetal, 2003 dalam Jirasukprasert et al., 2014).

Improve. Tahap ini berfokus pada penggunaan eksperimen dan statistik teknik untuk menghasilkan perbaikan mungkin untuk mengurangi jumlah kualitas masalah dan atau cacat (Omachonu dan Ross, 2004 dalam Jirasukprasert et al., 2014).

Control. Akhirnya, tahap terakhir ini dalam proses DMAIC memastikan bahwa perbaikan berkelanjutan (Omachonu dan Ross, 2004) dan yang sedang berlangsung Kinerja dimonitor. Proses perbaikan juga didokumentasikan dan dilembagakan (Stamatis, 2004 dalam Jirasukprasert et al., 2014).

\section{Tools Six Sigma DMAIC \\ Tahap Define \\ Pernyataan masalah}

Pernyataan masalah disusun dengan mempertimbangkan aspek dari periode waktu, spesifisitas dan pengukuran (Snee, 2001dalam Prashar 2014)

\section{Pernyataan tujuan}

Proyek harus ditetapkam untuk setiap proyek Six Sigma yang terpilih. Pernyataan tujuan yang benar adalah apabila mengikuti prinsip SMART (Spesific, Measurable, Achievable, Result Oriented, Time-bound) (Gaspers, 2002).

\section{Diagram SIPOC}

Diagram Sipoc digunakan untuk menyajikan sekilas dari aliran kerja.SIPOC digunakan untuk memastikan bahwa semua orang akan melihat proses dalam cara pandang yang sama ( Pande et al., 2002). Nama SIPOC merupakan akronim dari lima elemen utama dalam sistem kualitas, yaitu: Suppliers, Inputs, Process, Outputs, Customers (Gasperz, 2002).

\section{Tahap Measure}

\section{Identifikasi $C T Q$}

CTQ (Critical to Quality) merupakan atribut- atribut yang penting yang karena berkaitan langsung dengan kepuasan pelanggan, yang merupakan elemen dari suatu produk, proses atau praktek- pratek yang berdampak pada kualitas (Gasperz, 2002).

\section{Base line sigma level}

Tingkat sigma ini dihitung untuk atribut CTQ berdasarkan metode defect per million opportunities (DPMO) (Benbow dan Kubiak, 2010 dalam Prashar 2014).

\section{Tahap Anaylise}

\section{Cause and Effect (Ishikawa Diagram)}

Diagram berbentuk seperti kerangka ikan dengan kepala ikan yang memuat permasalahan dan tulang ikan yang memuat penyebab dari masalah,dan tulang yang lebih 
kecil memuat sub penyebab.Diagram ikan menggambarkan mengapa (why) situasi itu terjadi (Foster, 2013)

\section{Pareto Analysis}

Pareto charts digunakan untuk mengidentifikasi dan memprioritaskan masalah yang akan dipecahkan (Foster, 2013).

\section{Tahap Improve}

\section{FMEA}

FMEA (Failure Model and Effect Analysis) analisis kualitas terkait faktor yang lunak / dapat diatur-atur.

Menurut Pahl dan Beitz. FMEA adalah "Metode analisis formal untuk identifikasi sistematis terkait efek kemungkinan kegagalan dan estimasi risiko. Modus kegagalan ditentukan probabilitas Occurance $(\mathrm{O})$, skor untuk keseriusan efek Severity (S), dan skor untuk Detectability kegagalan selama desain (D). Nilai untuk O, S dan D biasanya berkisar dari 1 sampai 10, Risk Priority Number (RPN) dihitung dengan mengalikan O, S dan D, dan digunakan sebagai metrik untuk mengukur pentingnya kegagalan komponen (Renu et al, 2016).

\section{Tahap Control}

Tahap kontrol melibatkan mengelola proses peningkatan menggunakan proses grafik dan melaksanakan rencana kontrol. Untuk mempertahankan peningkatan tingkat sigma dari proses, tindakan pengendalian direkomendasikan oleh tim proyek.

\section{Metode Penelitian \\ Pendekatan Penelitian}

Pendekatan penelitian ini digunakan metode studi kasus deskrptif peneliti berupaya menelaah sebanyak munkin mengenai subjek yang diteliti. Metode yang sering diguanakan wawancara, observasi, penelaah dokumen, hasil survei dan data apapun yang menguraikan suatu kasus secara terperinci. (Mulyana, 2004). Penelitian ini memiliki tahapan sebagai berikut gambar 3.1 . 


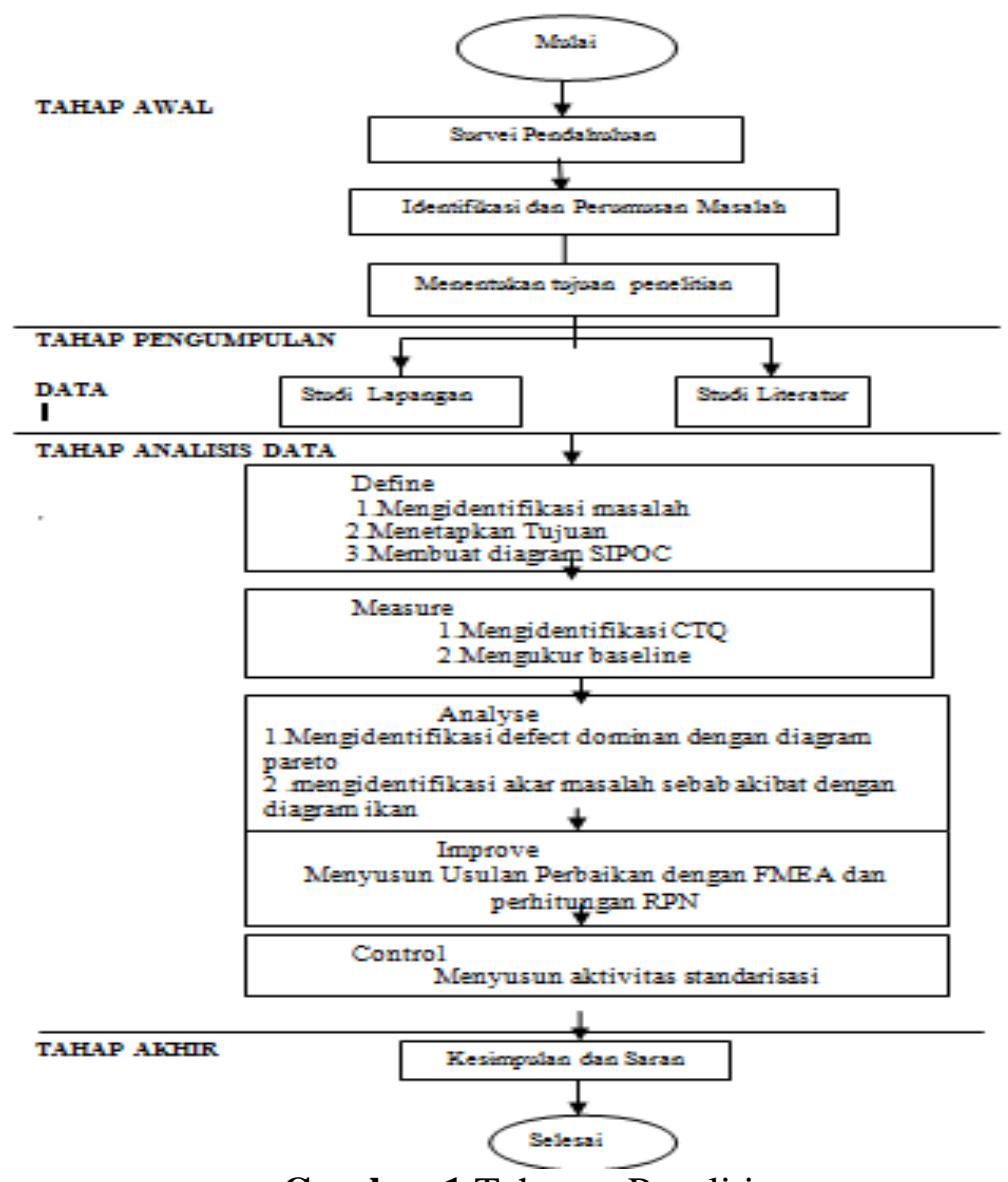

Gambar 1 Tahapan Penelitian

\section{Hasil dan Pembahasan}

\section{Gambaran Umum Profil Perusahaan}

Perusahaan Daerah Air Minum (PDAM) Surya Sembada Kota Surabaya yang terlatak di daerah Surabaya jawa timur adalah perusahaan yang telah berdiri pada tanggal 30 Maret tahun 1976 berdasarkan peraturan daerah No. 7 dan dimiliki oleh pemerintah Surabaya. Disahkan dengan Surat Keputusan Gubernur Kepala Daerah tingkat I Jawa Timur,tanggal 06 November 1976 No. II/155/76 dan diundangkan dalam Lembaran Daerah Kotamadya Daerah Tingkat II Surabaya tahun 1976 seri C pada tanggal 23 November 1976 No. 4/C. PDAM Surya Sembada Kota Surabaya melakukan bisnis pengelolahan dan distribusi air bersih bagi masyarakat Surabaya dan mengembangkan jaringannya hingga Pasuruan, dan Sidoarjo.

\section{Visi Misi Perusahaan}

Visi

Tersedianya Air Minum yang Cukup Bagi Pelanggan Melalui Perusahaan Air Minum yang Mandiri, Berwawasan Global, dan Terbaik di Indonesia.

\section{Misi}

1. Memproduksi dan Mendistribusikan Air Minum bagi Pelanggan.

2. Memberi Pelayanan Prima bagi Pelanggan dan bagi para pemangku kepentingan.

3 .Melakukan Usaha lain bagi kemajuan perusahaaan dan berpartisipasi aktif dalam Kegiatan Sosial Kemasyarakatan 


\section{Struktur Organisasi PDAM Surya Sembada Kota Surabaya}

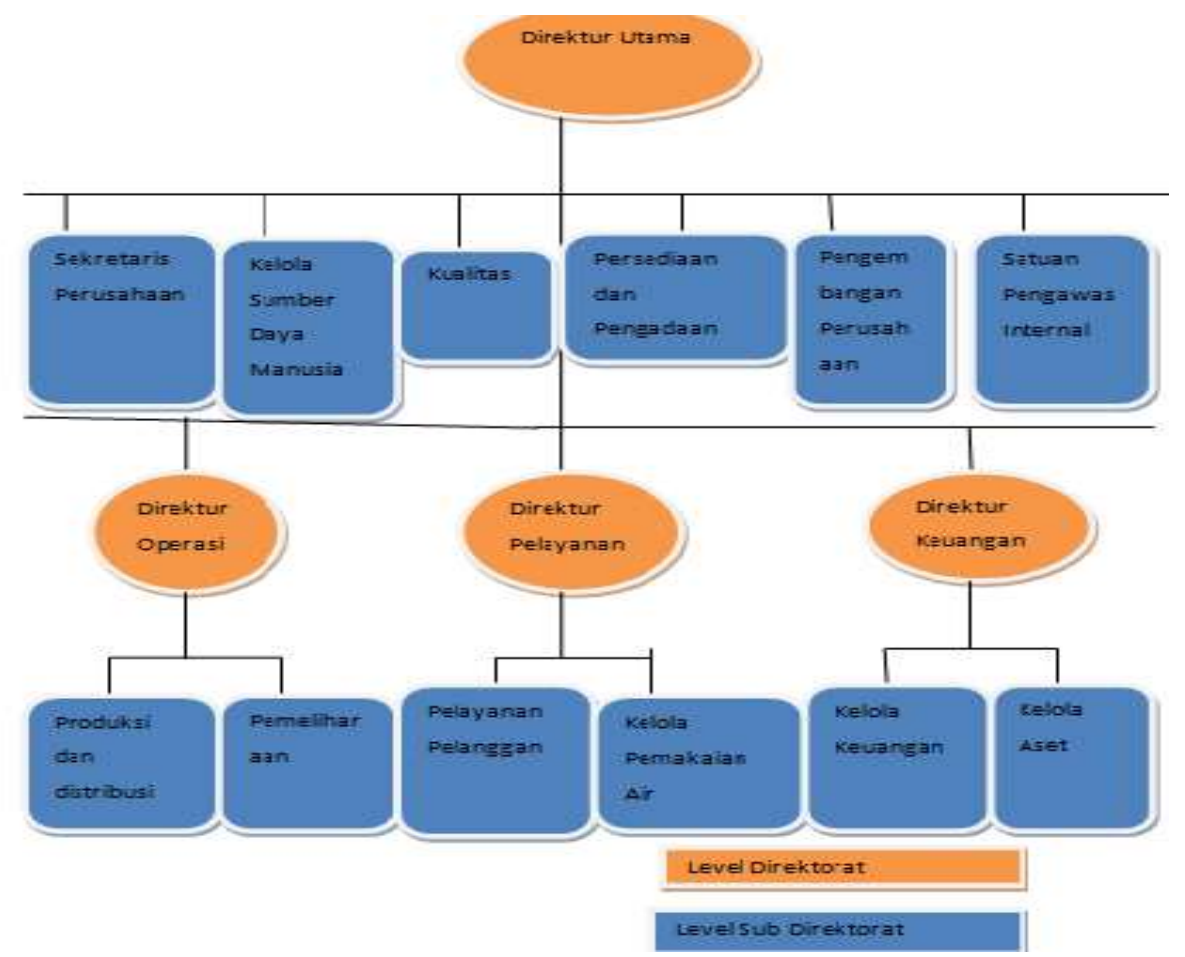

Gambar 2. Struktur Organisasi PDAM Surya Sembada Kota Surabaya (Sumber: Company profile perusahaan)

\section{Proses Distribusi Air PDAM Surya Sembada Kota Surabaya}

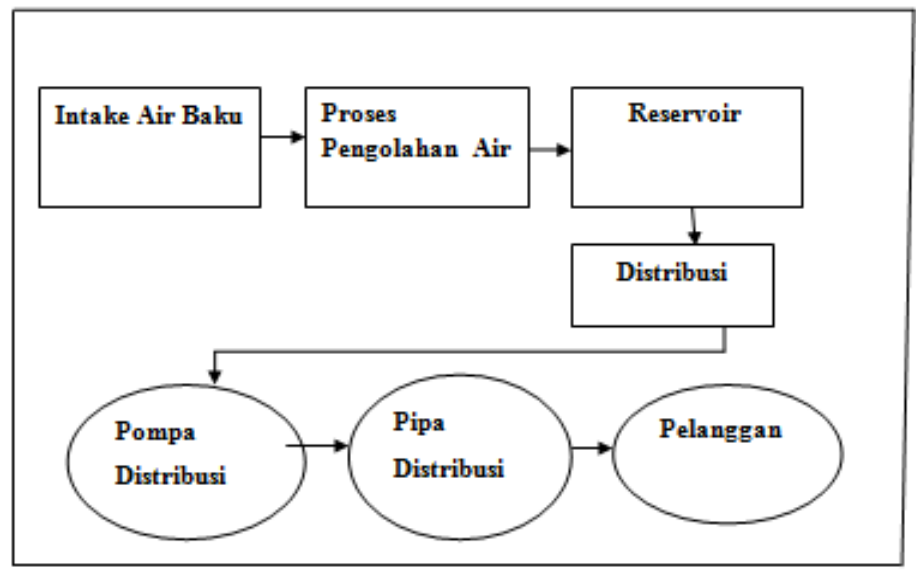

Gambar 3. Proses Distribusi Air PDAM Surya Sembada Kota Surabaya (Sumber: Data Perusahaan yang diolah.)

Dalam gambar diatas dilukiskan suatu sistem pengelolahan air bersih. Air baku kali brantas mengalir dari anak sungai, kemudian di bendung dalam Intake dialirkan ke sistem pengelolahan. Sistem Pengolahan Air terdiri dari satuan operasi dan satuan proses yang mencakup unit aerasi, unit pre-sedimentasi, unit koagulasi dan flokulasi, unit sedimentasi, unit filtrasi, unit disinfeksi. Kemudian air dialirkan menuju reservoir kemudian air siap untuk di distribusikan. Distribusi air dengan pompa distribusi, pipa distribusi yang terdiri dari pipa primer, sekunder, tersier, pelayanan pelanggan. 


\section{Hasil dan Pembahasan}

Setelah dilakukan penelitian dan pengumpulan data,maka pada bab ini akan dilakukan pengolahan dan analisa terhadap data tersebut.Pengolahan dan analisa data dilakukan dengantahap define, measure, anlyse, improve, dan control.Hasil pembahasan sebagai berikut.

\section{Tahap Define}

Tahap define merupakan langkah awal dalam analisis Six sigma pada Kualitas Distribusi air PDAM Surya Sembada Kota Surabaya langka ini dimulai dengan pernyataan masalah yang terjadi, pernyataan misi, dan membuat diagram SIPOC untuk mengidentifikasi pihak-pihak yang terlibat pada aliran kerja PDAM Surya Sembada Kota Surabaya.

\section{Pernyataan masalah}

Pada PDAM Surya Sembada Kota Surabaya masih terdapat defect (pelanggan belum puas). Hal ini terlihat dengan masih adanya keluhan pelanggan terhadap PDAM. Berikut data tentang defect yang terjadi pada periode tahun 2015 dapat dilihat pada gambar 3 dan tabel 1.

Tabel 1

Keluhan Pelanggan PDAM Surya Sembada Kota Surabaya Periode Tahun 2015

\begin{tabular}{|l|c|c|c|c|}
\hline \multirow{2}{*}{ Periode } & \multirow{2}{*}{$\begin{array}{c}\text { Jumlah } \\
\text { Pelanggan }\end{array}$} & TDA & AKB & Total \\
\cline { 3 - 5 } & 526.498 & 339 & 98 & 437 \\
\hline Januari & 527.208 & 268 & 83 & 351 \\
\hline Februari & 527.963 & 517 & 179 & 696 \\
\hline Maret & 528.952 & 542 & 115 & 657 \\
\hline April & 530.014 & 659 & 101 & 760 \\
\hline Mei & 531.115 & 1257 & 84 & 1341 \\
\hline Juni & 532.313 & 579 & 66 & 645 \\
\hline Juli & 533.064 & 771 & 116 & 887 \\
\hline Agustus & 533.936 & 898 & 75 & 973 \\
\hline September & 534.95 & 1190 & 92 & 1282 \\
\hline Oktober & 536.216 & 1307 & 198 & 1505 \\
\hline November & 5367 & 145 & 1235 \\
\hline Desember & 536.989 & 1090 & $\mathbf{1 3 5 2}$ & $\mathbf{1 0 7 6 9}$ \\
\hline Total & $\mathbf{6 . 3 7 9 . 2 1 8}$ & $\mathbf{9 4 1 7}$ & &
\end{tabular}

Sumber: Data Intern Perusahaan yang diolah.

\section{Pernyataan Misi}

Pernyataan tujuan proyek Six Sigma Pdam Surya Sembada Surabaya jika mengikuti prinsip SMART adalah sebagai berikut:

1. Spesific. Melakukan rencana perbaikan proses perbaikan layanan produk distribusi air bersih untuk mengurangi gangguan yang terjadi, sehingga konsumen bisa menikmati air bersih.

2. Measurable. Penurunan jumlah defect yang terjadi selama proses distribusi selanjutnya setelah adanya upaya perbaikan.

3. Achievable. Dalam upaya peningkatan kualitas, target yang hendak dicapai sekiranya dapat terjangkau oleh tim.

4. Result Oriented. Tujuan penurunan jumlah defect sesuai dengan target yang telah ditetapkan ditunjukkan dengan adanya penurunan DPMO. 
5. Time-bound. Peningkatan kualitas pelayanan harus menetapkan batas-batas waktu pencapaian tujuan itu dan harus dicapai secara tepat waktu.

\section{SIPOC}

SIPOC digunakan untuk menyajikan sekilas dari aliran kerja untuk memastikan bahwa semua orang (Pande et all, 2002). Berikut Diagram SIPOC PDAM Surya Sembada Kota Surabaya dapat dilihat pada tabel 2.

Tabel 2. Diagram SIPOC PDAM Surya Sembada Kota Surabaya

\begin{tabular}{|c|c|c|c|c|}
\hline Supplier & Input & Process & Output & Customers \\
\hline $\begin{array}{l}\text { Perusahaan } \\
\text { Jasa Tirta }\end{array}$ & Menyediakan air & $\begin{array}{c}\text { Air baku } \\
\downarrow\end{array}$ & Air bersih & $\begin{array}{l}\text { Kelompok } \\
\text { Pelangean I }\end{array}$ \\
\hline PU & $\begin{array}{l}\text { Mengelolah } \\
\text { pengambilan } \\
\text { meter air komersil } \\
\text { dan nonkomersil }\end{array}$ & $\begin{array}{c}\downarrow \\
\text { Pengolahan Air } \\
\text { Baku } \\
\downarrow \\
\text { Pipa Transmisi }\end{array}$ & & $\begin{array}{l}\text { Pelanggan II } \\
\text { Kelompok } \\
\text { Pelanngan III } \\
\text { Kelompok } \\
\text { Pelanggan IV }\end{array}$ \\
\hline Bappeda & $\begin{array}{l}\text { Pengembangan } \\
\text { zona }\end{array}$ & $\begin{array}{c}\text { Reservoir } \\
\downarrow \\
\text { Pompa distribusi }\end{array}$ & & $\begin{array}{l}\text { Pelanggan V } \\
\text { Kelompol } \\
\text { Pelanggan VI }\end{array}$ \\
\hline PLN & $\begin{array}{l}\text { Menyediakan } \\
\text { listrik }\end{array}$ & $\stackrel{\downarrow}{\downarrow}$ & & $\begin{array}{l}\text { Kelompok } \\
\text { Pelanggan VII } \\
\text { Kelompok }\end{array}$ \\
\hline $\begin{array}{l}\text { Supplier } \\
\text { Bahan Kimia }\end{array}$ & $\begin{array}{l}\text { Menyediakan } \\
\text { bahan kimia }\end{array}$ & $\begin{array}{c}\text { Air Sampai ke } \\
\text { Pelanggan }\end{array}$ & & $\begin{array}{l}\text { Pelanggan } \\
\text { VIII } \\
\text { Kelompok }\end{array}$ \\
\hline $\begin{array}{l}\text { Kontraktor } \\
\text { Pipa }\end{array}$ & Instalasi Pipa & & & $\begin{array}{l}\text { Pelanggan IX } \\
\text { Kelompok } \\
\text { Pelanggan X } \\
\text { Kelompok } \\
\text { Pelanggan XI }\end{array}$ \\
\hline
\end{tabular}

Sumber: Data intern Perusahaan yang diolah.

NB: Klasifikasi Pelanggan pada PDAM Surya Sembada Kota Surabaya berdasarkan Peraturan perusahaan, PDAM Kota Surabaya No.4 Tahun 2008 tanggal 3 maret 2008 tentang klasifikasi Kelompok Pelanggan Air Minum.

\section{Tahap Measure}

Pada tahap ini mengumpulkan data dan mengidentifikasi CTQ (Critical to Quality) mengukur kinerja distribusi air yang dinyatakan dalam DPMO (Deffect Per Million Oppurtunity) dan dikonversikan dalam nilai sigma.

\section{Identifikasi CTQ}

CTQ potensial pada penelitian ini ada 2, yaitu kondisi kualitas air tidak sesuai dengan harapan pelanggan karena Air keruh bau dan TDA (air keluar kecil atau air tidak keluar sama sekali). 


\section{Base line sigma level}

Tingkat sigma ini dihitung untuk atribut CTQ berdasarkan metode defect per million opportunities (DPMO). Data jumlah keluhan pelanggan digunakan untuk menentukan nilai DPMO dan nilai kapabilitas sigma pada tabel 3.

Tabel 3. Kapabilitas Sigma dan DPMO dari Proses Distribusi Air PDAM Surya Sembada Kota Surabaya Periode Tahun 2015

\begin{tabular}{|c|c|c|c|c|c|c|}
\hline Periode & $\begin{array}{l}\text { Jumlah } \\
\text { Pelanggan }\end{array}$ & $\begin{array}{l}\text { Jumlah } \\
\text { Gangguan }\end{array}$ & CTQ & DPO & DPMO & Sigma \\
\hline Januari & 526.498 & 437 & 2 & 0,000415 & 415 & 4,84 \\
\hline Februari & 527.208 & 351 & 2 & 0,000332 & 332 & 4,90 \\
\hline Maret & 527.963 & 696 & 2 & 0,000659 & 659 & 4,71 \\
\hline April & 528.952 & 657 & 2 & 0,000621 & 621 & 4,73 \\
\hline Mei & 530.014 & 760 & 2 & 0,000716 & 716 & 4,69 \\
\hline Juni & 531.115 & 1341 & 2 & 0,001262 & 1262 & 4,52 \\
\hline Juli & 532.313 & 645 & 2 & 0,000605 & 605 & 4,73 \\
\hline Agustus & 533.064 & 887 & 2 & 0,000831 & 831 & 4,64 \\
\hline September & 533.936 & 973 & 2 & 0,000877 & 877 & 4,63 \\
\hline Oktober & 534.95 & 1282 & 2 & 0,001198 & 1198 & 4,54 \\
\hline November & 536.216 & 1505 & 2 & 0,001403 & 1403 & 4,48 \\
\hline Desember & 536.989 & 1235 & 2 & 0,001149 & 1149 & 4,55 \\
\hline \multicolumn{7}{|c|}{ Keterangan Perhitungan: } \\
\hline \multicolumn{7}{|c|}{ Ilustrasi Contoh Perhitungan } \\
\hline \multicolumn{7}{|c|}{ Bulan Januari 2015} \\
\hline \multicolumn{7}{|c|}{101, (2) } \\
\hline \multicolumn{7}{|c|}{$-\quad \mathrm{DPMO}=[437 /(526.498 \times 2)] \times 1.000 .000=415$} \\
\hline \multicolumn{7}{|c|}{ - $\quad$ Diketahui bahwa nilai sigma adalah nilai } \\
\hline \multicolumn{7}{|c|}{ yang paling dekat dengan DPMO $=4,84$} \\
\hline \multicolumn{7}{|c|}{$\begin{array}{l}-\quad \text { (Tabel konversi DPMO ke nilai sigma dapat dilihat pada } \\
\text { lampiran). }\end{array}$} \\
\hline
\end{tabular}

Sumber: Data Intern Perusahaan yang diolah.

Dari Tabel DPMO dan nilai sigma proses kualitas distribusi air menunjukkan bahwa tingkat DPMO sangat fluktuatif, dimana terdapat titik DPMO yang paling tinggi yaitu sebesar 1.403 dengan kapabilitas sigma paling rendah 4,48 sigma dan titik DPMO yang paling rendah yaitu sebesar 332 dengan kapabilitas sigma paling tinggi 4,90 sigma. Hal ini menunjukkan bahwa pengelolaan proses distribusi air belum dikelola secara tepat. Apabila proses distriusi air dikelola dengan baik, maka akan menunjukkan pola kapabilitas sigma yang terus meningkat sepanjang waktu. 
Tabel 4.

Kapabilitas Proses Distribusi Air PDAM Surya Sembada Kota Surabaya Tahun 2015

\begin{tabular}{|c|c|c|c|}
\hline Langkah & Tindakan & Persamaan & $\begin{array}{c}\text { Hasil } \\
\text { Perhitungan } \\
\end{array}$ \\
\hline 1 & $\begin{array}{l}\text { Proses apa yang Anda } \\
\text { ingin ketahui? }\end{array}$ & & $\begin{array}{c}\text { Kualitas } \\
\text { distribusi Air }\end{array}$ \\
\hline 2 & $\begin{array}{l}\text { Berapa banyak unit } \\
\text { produk yang diperiksa? }\end{array}$ & & 6.379 .218 \\
\hline 3 & $\begin{array}{l}\text { Berapa banyak unit } \\
\text { produk yang gagal atau } \\
\text { cacat? }\end{array}$ & & 10769 \\
\hline 4 & $\begin{array}{l}\text { Hitung tingkat cacat } \\
\text { (kegagalan) } \\
\text { berdasarkan pada } \\
\text { tingkat } 3\end{array}$ & $\begin{array}{l}=(\text { langkah } 3) / \\
(\text { langkah } 2)\end{array}$ & 0,001688 \\
\hline 5 & $\begin{array}{l}\text { Tentukan banyaknya } \\
\text { CTQ potensial yang } \\
\text { dapat mengakibatkan } \\
\text { cacat (kegagalan) }\end{array}$ & $\begin{array}{l}\text { = banyaknya } \\
\text { karakteristik } \\
\text { CTQ }\end{array}$ & 2 \\
\hline 6 & $\begin{array}{l}\text { Hitung peluang tingkat } \\
\text { cacat per satu juta } \\
\text { kesempatan (DPMO) }\end{array}$ & $\begin{aligned}= & (\text { langkah 4) / } \\
& (\text { langkah 5) }\end{aligned}$ & 0,000844 \\
\hline 7 & $\begin{array}{l}\text { Hitung kemungkinan } \\
\text { cacat (kegagalan) per } \\
\text { karakteristik CTQ }\end{array}$ & $\begin{array}{c}=(\text { langkah 6) } \mathrm{x} \\
1.000 .000\end{array}$ & 844 \\
\hline 8 & $\begin{array}{l}\text { Konversi DPMO } \\
\text { (langkah 7) ke dalam } \\
\text { nilai sigma }\end{array}$ & & 4,64 \\
\hline 9 & Buat kesimpulan & & $\begin{array}{l}\text { Kapabilitas } \\
\text { Sigma adalah } \\
4,64\end{array}$ \\
\hline
\end{tabular}

Sumber: Data intern perusahaan yang telah diolah.

\section{Tahap Analyze}

Dalam tahap ini, dicari penyebab defect utama menggunakan analisis pareto dan analisis terhadap penyebab defect menggunakan diagram sebab dan akibat.

\section{Diagram Pareto}

Dari dua jenis cacat yang terjadi, cacat yang paling sering terjadi adalah TDA menyusul kemudia air keruh bau.dengan presentase dari keseluruhan total cacat 10769. Cacat TDA yang terjadi sebesar 9417 atau 87\% dari keseluruhan total cacat dan kemudian.Air Keruh bau jenis cacat yang terjadi sebesar 1352 atau 13\% dari keseluruhan total cacat yang terjadi. 


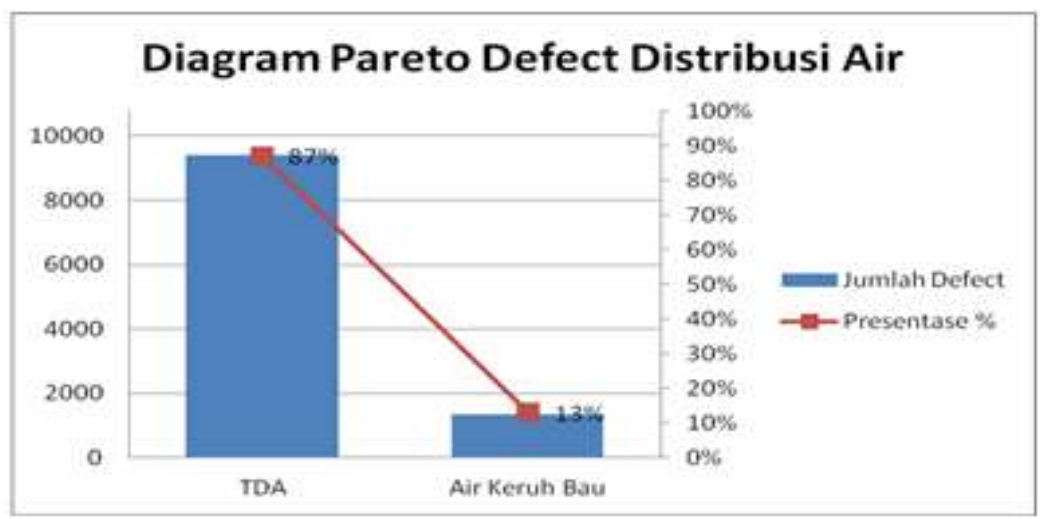

Gambar 4. Diagram Pareto Defect Distribusi Air PDAM Surya Sembada Kota Surabaya (Sumber: Data Intern Perusahaan yang telah diolah.)

\section{Diagram Cause and Effect (Ishikawa Diagram)}

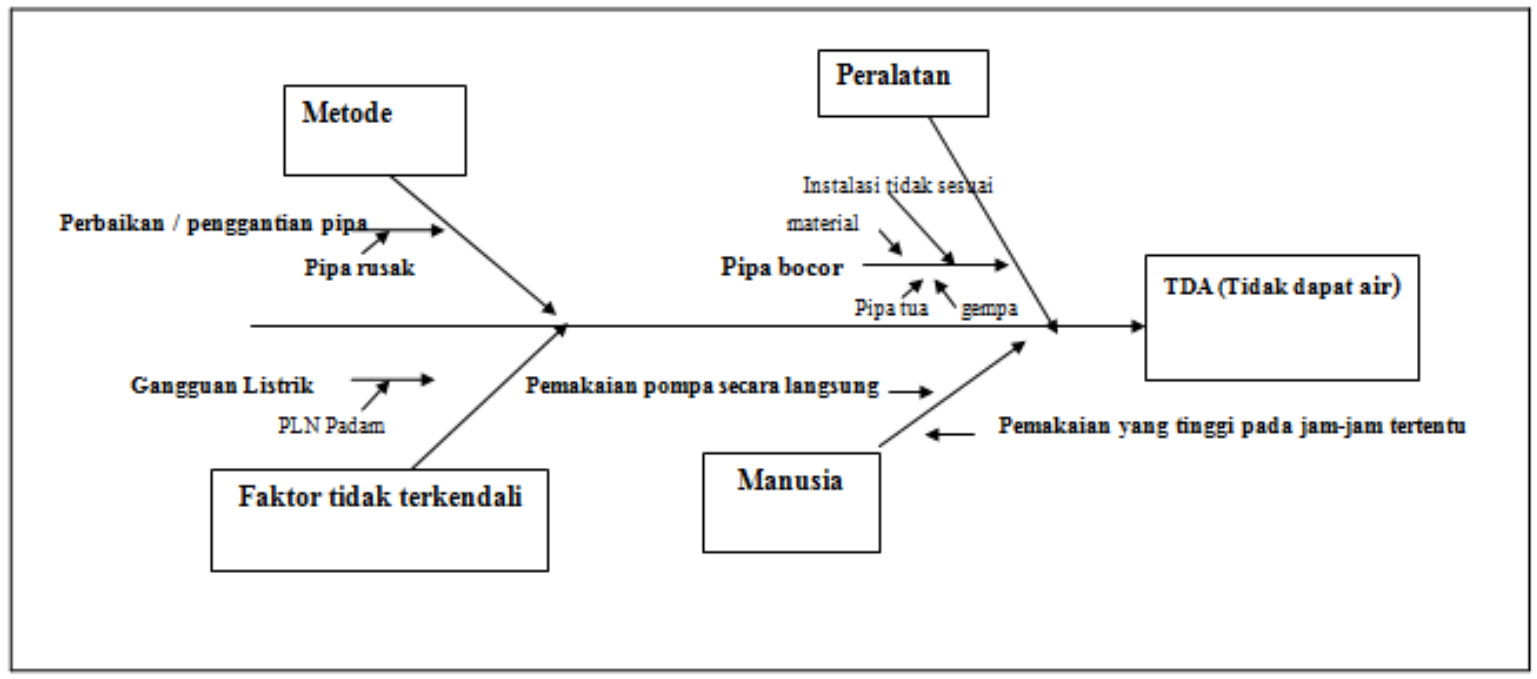

Gambar 5. Diagram cause and Effect Penyebab TDA

(Sumber: Data Intern Perusahaan yang telah diolah.)

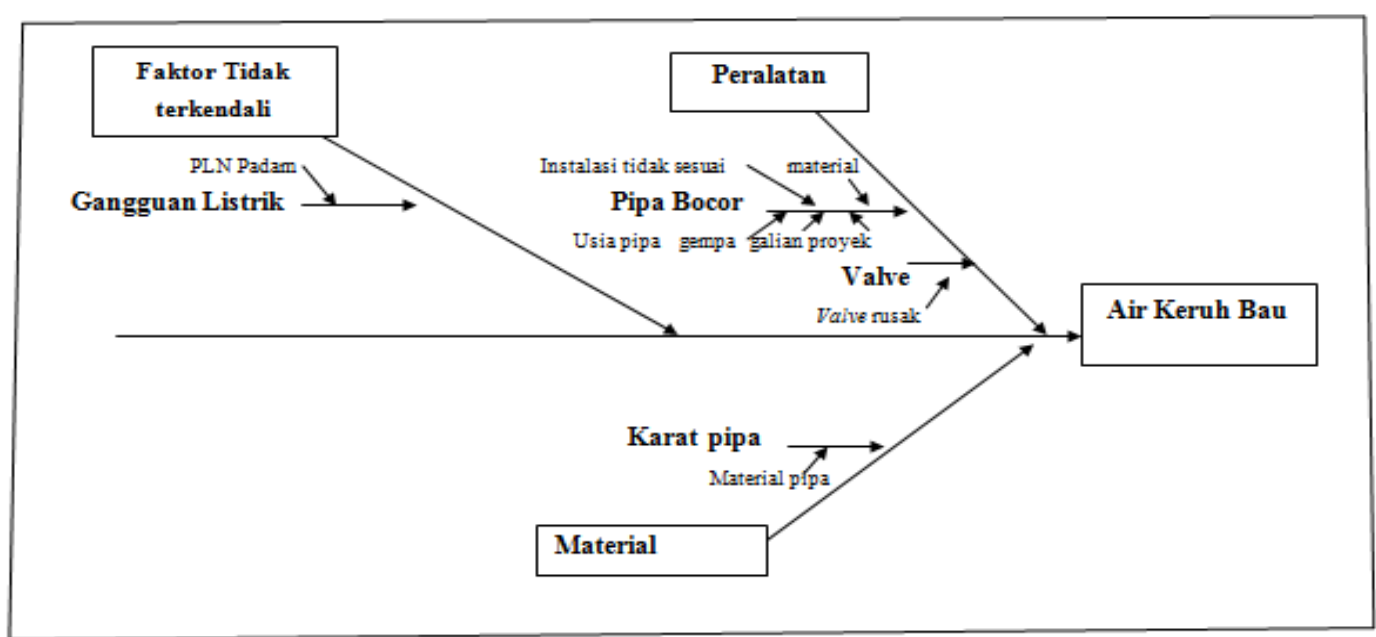

Gambar 6. Diagram Cause and Effect untuk AKB

(Sumber: Data Intern Perusahaan yang telah diolah.) 


\section{Tahap Improve}

Dalam tahap ini setelah diketahui penyebab defect maka disusunlah tabel FMEA sebagai tools untuk proses perbaikan.

\section{Analisis FMEA}

Setalah dianalisis penyebab terjadinya defect maka disusunlah FMEA sebagai tools untuk perbaikan kualitas.

Tabel 5. Prioritas Perbaikan untuk TDA Berdasarkan dari kompilasi FMEA

\begin{tabular}{|c|c|l|}
\hline No & RPN & \multicolumn{1}{|c|}{ Tindakan Perbaikan } \\
\hline 1 & 192 & $\begin{array}{l}\text { Teguran dan sanksi dari Pihak PDAM karena tindakan tersebut } \\
\text { merugikan pelanggan lain. }\end{array}$ \\
\hline 2 & 192 & Menambah Supplai kapasitas air \\
\hline 3 & 160 & $\begin{array}{l}\text { Melakukan penilaian dan melakukan pergantian pada material yang } \\
\text { rusak }\end{array}$ \\
\hline 4 & 72 & $\begin{array}{l}\text { Menyelesaikan pengerjaan perbaikan pipa dengan sesegera mungkin. } \\
\text { Upaya pencegahan terhadap kerusakan pipa lebih diutamakan. }\end{array}$ \\
\hline
\end{tabular}

Sumber: Data Intern Perusahaan yang telah diolah.

Penjelasan menegenai usulan perbaikan untuk mengurangi defect TDA pada tabel 4.7 adalah sebagai berikut:

1. Perbaikan yang pertama dengan memeberikan sanksi dan teguran kepada pelanggan maupun non pelanggan yang bertindak merugikan pelanggan dan pihak PDAM Surya Sembada Kota Surabaya dengan demikian hak pelanggan tetap terjaga.

2. Perbaikan Kedua dengan menambah supplai kapasitas air. Sehingga air yang dialirkan akan lebih banyak.

3. Perbaikan yang ketiga Melakukan penilaian dan melakukan pergantian pada material yang rusak dengan demikian performance dari fungsi alat tersebut berada pada performance terbaik.

Tabel 6.Prioritas Perbaikan untuk AKB berdasarkan dari kompilasi FMEA

\begin{tabular}{|l|l|l|}
\hline No & RPN & Tindakan Perbaikan \\
\hline $\mathbf{1}$ & $\mathbf{1 4 4}$ & Mengganti valve yang rusak. \\
\hline $\mathbf{2}$ & $\mathbf{1 2 0}$ & $\begin{array}{l}\text { Melakukan penilaian dan melakukan pergantian } \\
\text { pada material yang rusak (pipa) }\end{array}$ \\
\hline $\mathbf{3}$ & $\mathbf{3 0}$ & $\begin{array}{l}\text { Tidak menggunakan bahan pipa yang rawan } \\
\text { berkarat (galvanis). }\end{array}$ \\
\hline
\end{tabular}

Sumber: Data Intern Perusahaan yang telah diolah.

Penjelasan menegenai usulan perbaikan untuk mengurangi defect AKB pada Tabel 4.8 adalah sebagai berikut:

1. Perbaikan yang pertama yaitu melakukan penggantian valve yang rusak. Dengan demikian fungsi valve akan kembali normal.

2. Perbaikan yang kedua Melakukan penilaian dan melakukan pergantian pada material yang rusak. Dengan demikian performance dari fungsi alat tersebut berada pada performance terbaik. 
3. Perbaikan yang ketiga tidak menggunakan bahan yang rawan berkarat. Sehingga memperkecil efek terjadinya karat yang dapat menyebabkan air keruh bau.

\section{Tahap Control}

Setelah menyusun rencana perbaikan pada tahap improve menggunkan analisa FMEA, maka pada tahap control untuk mempertahankan peningkatan sigma dari proses, tindakan yang diharapkan dapat mengurangi atau mencegah terjadinya defect terjadi antara lain:

1. pemeliharaan dan Penilaian Kondisi jaringan peralatan distribusi secara rutin. Untuk mencapai fungsi jaringan yang baik sehingga mencapai mutu distribusi air yang baik juga.

2. Pencatatan meter air secara rutin dan terjadwal oleh petugas. Untuk menghindari terjadinya kecurangan atau perilaku yang dapat merugikan pihak PDAM Surya Sembada Kota Surabaya maupun Pelanggan yang lain.

3. Menggunakan material pipa yang tidak mudah korosif.

\section{Kesimpulan dan Saran \\ Kesimpulan}

Pada bab IV telah dilakukan analisis kualitas dan perancangan perbaikan kualitas distribusi air pada PDAM Surya Sembada Kota Surabaya dengan menggunakan metode DMAIC Six Sigma, maka dapat disimpulkan bahwa:

1. Pada tahap define dilakukan pernyataan masalah, pernyataan tujuan dan identifikasi proses distribusi air dari pihak-pihakyang terlibat dalam SIPOC.

2. Pada tahap measure dialkuakn identifikasi CTQ, dimana telah ditemukan 2 CTQ yang berpengaruh pada kepuaan pelanggan yakni: Air Keruh Bau dan Tidak Dapat Air. Pada tahap ini juga dilakukan pengukuran baseline kinerja dari proses distribusi air periode tahun 2015 dengan menghitung nilai DPMO dan level sigma,serta dilakukan perhitungan rata-rata nilai DPMO dan level sigma diperoleh nilai DPMO 844 dan level sigma 4,64.

3. Pada tahap analyze dilakukan analisis CTQ dominan menggunakan diagram pareto dan identifikasi penyebab masalah dengan cause and effect diagram.

4. Pada tahap improve dilakukan usulan perbaikan menggunakan FMEA dan prioritas perbaikan berdasarkan nilai RPN tertinggi.

5. Pada tahap control dilakukan pengontrolan aktivitas untuk mencegah kesalahan yang lama terulang kembali, yaitu dengan penialian dan pemeliharaan jaringan distribusi secara rutin dan pencatan meter air oleh petugas secara terjadwal.

\section{Saran}

Berdasarkan kesimpulan yang diperoleh, maka penulis ingin memberikan saran kepada perusahaan dan peneliti lain yang akan melakukan penelitian dibidang yang sama:

1. PDAM Surya Sembada Kota Surabaya untuk mempertahankan dan meningkatkan kinerja agar lebih baik lagi.

2. Setelah diketahui penyebab dari adanya defect maka dapat dilakukan tindakan korektif untuk meminmalisir defect yang terjadi.

3. PDAM Surya Sembada Kota Surabaya dapat melaksanakan usulan perbaikan yang telah diajukan secara berkala dan berkelanjutan. 
4. Diharapkan untuk Peneliti Selanjutnya dapat menerapkan six sigma DMAIC di berbagai tahapan proses.

\section{Daftar Pustaka}

Besterfield. 2003. Total Quality Management. 3th Edition.United States of America: PearsonPrantice Hall

Company Profile .2015. PDAM Surya Sembada Kota Surabaya. Surabaya

Foster, S. Thomas. 2013. Managing Quality: Integrating The Supply Chain. Fifth Edition. New Jersey: Pearson Education, Inc.

Gasperz. 2002. Pedoman Implementasi Program Six Sigma-Terintegrasi dengan ISO 9001:2000, MBQNA, dan HACCP. Jakarta: PT Gramedia Pustaka Utama.

Hakserver, C ., Render B.2013. Service Management: An Integrated Approach to Supply Chain Management and Operations:Pearson Education, Inc.

Jirasukprasert, P., Arturo Garza-Reyes, J., Kumar, V., dan K. Lim, M. (2014). A Six Sigma and DMAIC application for the reduction of defects in a rubber gloves manufacturing process. International Journal of Lean Six Sigma, 5(1), 2-21.

Kotler, P., \& Keller, Kevin L.2009.Marketing Management. 13th Edition. New Jersey: Pearson Prentice Hall.

Mulyana,Deddy. 2004. Metedologi Penelitian Kualitatif. Bandung: Remaja Rosdakarya.

Nasution, M. N. 2005. Manajemen Mutu Terpadu (Total Quality Management). Ghalia Indonesia, Bogor.

Pande, Peter S., Robert P. Neuman, and Roland R. Cavanagh. 2000. The Six Sigma Way. United States of America: McGraw-Hill..

-2002.The Six Sigma Way:Bagaimana GE dan Perusahaan terkenal lainnya meningkatkan kinerja mereka. Andi.Yogyakarta

Prashar Anupama, (2014), "Adoption of Six Sigma DMAIC to reduce cost of poor quality", International Journal of Productivity and Performance Management, Vol. 63 Iss 1 pp. $103-126$.

Renu et al. 2016. A Knowledge Based FMEA to Support Identification and Management of Vehicle Flexible Component Issues. 6th CIRP Conference on Assembly Technologies and Systems (CATS).Vol 44.157-162.

Sebastianelli, R., \& Tamimi, N. 2002. How product quality dimensions relate to defining quality. The International Journal of Quality \& Reliability Management, Vol 19,Iss 4.

Srinivasan, K et al. 2014. Reduction of paint line defects in shock absorber through six sigma dmaic phases.12 th Global Congress on Manufacturing and management, Vol 97, pp $1755-1764$. 